\title{
O DESENVOLVIMENTO CONSTITUCIONAL DOS DIREITOS SEXUAIS NO \\ BRASIL: UM EXAME DOS ELEMENTOS FUNDAMENTAIS E ESTRUTURANTES \\ DA ORDEM DEMOCRÁTICA DO EXERCÍCIO DA SEXUALIDADE
}

\author{
THE CONSTITUTIONAL HISTORIOGRAPHY OF THE LEGAL CONTENT OF \\ SEXUAL RIGHTS IN BRAZIL: AN ANALYSIS OF THE BASIS AND \\ FUNDAMENTALS OF THE DEMOCRATIC SEXUAL FREEDOM
}

\author{
Silvio Romero Beltrão ${ }^{1}$ \\ Luís Eduardo e Silva Lessa Ferreira ${ }^{2}$
}

\section{RESUMO}

Este artigo propõe o estudo dos conteúdos materiais e adjetivos que compõem os direitos sexuais, sob uma perspectiva de direitos humanos, como ferramentas de tutela da individualidade e dos bens coletivos referentes ao livre exercício da sexualidade, e promoção dos valores de igualdade, dignidade e processos de cidadania. Através da inventariação multimetodológica das principais construções dos direitos sexuais, tanto no âmbito supranacional, quanto nacional, propõe-se a revisão de definições e conteúdos de direitos que compõem a construção jurídica dos "direitos sexuais democráticos".

Palavras-chave: Direitos humanos, Direito Constitucional, Direitos Fundamentais, Direitos sexuais, sexualidade.

\begin{abstract}
This article aims to review the legal basis of the substantive and adjective contents of the sexual rights as support for the judicial remedies to protect the individual and the social values of the free expression of one's sexuality, as means to promote the genuine exercise of citizenship and respect for human rights. It is exploratory of the definitions and of the contends of law that uphold the legal construction of the "democratic sexual rights", considering the progressive development of human rights, both nationally and internationally.
\end{abstract}

Keywords: Human rights, Constitutional law, Fundamental Rights, Sexual rights, Sexuality.

\footnotetext{
${ }^{1}$ Doutorado e Mestrado em Direito pela Universidade Federal de Pernambuco, Pós-Doutorado em Direito pela Faculdade de Direito da Universidade de Lisboa. Professor adjunto da Universidade Federal de Pernambuco. Juiz de Direito do Tribunal de Justiça do Estado de Pernambuco. Afiliação: Universidade Federal de Pernambuco UFPE, Pernambuco. ORCID: https://orcid.org/0000-0002-9548-5017

Lattes: http://lattes.cnpq.br/3476926796268243 E-mail: silviorb@gmail.com

${ }^{2}$ Doutorando e Mestre em Direito Privado pela UFPE. Afiliação: Universidade Federal de Pernambuco - UFPE, Pernambuco. ORCID: https://orcid.org/0000-0001-8224-7960 Lattes: http://lattes.cnpq.br/8055732282712161 Email: lessaluiseduardo@gmail.com
} 


\section{INTRODUÇÃO}

A expressão dos direitos sexuais é relativamente recente na pauta dos discursos jurídicos. Chamados de "The new kid on the block", têm, segundo Richard Parker (2007a, p. 972) maior repercussão através das abordagens teoréticas e metodológicas dos direitos humanos. Todavia, já guarda clara expressão nos diplomas legais vigentes nas ordens nacionais e internacionais, e também na similaridade de consensos desenvolvidos pela Organização das Nações Unidas, e organizações afins.

Segundo definição da Organização Mundial de Saúde ${ }^{3}$, os direitos sexuais significam “os direitos das pessoas, livre de coação, discriminação e violência, de manter o mais elevado grau de possibilidade o status de saúde sexual, incluindo o acesso aos serviços de saúde sexual e reprodução" (WHO, 2006, at. 2010).

Na extensão da definição proposta pela Organização Mundial de Saúde, apresentam-se como aspectos críticos para a realização dos direitos sexuais: o direito à igualdade e a nãodiscriminação, o direito de estar livre de tortura e práticas cruéis, desumanas ou degradantes, o direito à privacidade, o direito à informação e educação, o direito à liberdade de opinião e expressão; e, o direito a uma tutela efetiva de combate às violações de direitos fundamentais.

Outras definições incluem ainda a expressão democrática do direito sexual como a garantia de buscar, receber e passar adiante informações sobre sexualidade e o direito de receber educação sexual. Além das garantias de ver a sua integridade física respeitada e ter direito de escolha sobre a própria vida sexual (quantos as possibilidades de iniciar uma vida

\footnotetext{
${ }^{3}$ World Health Organization: Developing sexual health programmes - a framework for action, 2006. "There is a growing consensus that sexual health cannot be achieved and maintained without respect for, and protection of, certain human rights. The working definition of sexual rights given below is contribution to the continuing dialogue on human rights related to sexual health.. "The fulfilment of sexual health is tied to the extent to which human rights are respected, protected and fulfilled. Sexual rights embrace certain human rights that are already recognized in international and regional human rights documents and other consensus documents and in national laws. Rights critical to the realization of sexual health include: 1. Rights critical to the realization of sexual health include: 2. the rights to equality and non-discrimination 3. the right to be free from torture or to cruel, inhumane or degrading treatment or punishment 4. the right to privacy 5. the rights to the highest attainable standard of health (including sexual health) and social security 6. the right to marry and to found a family and enter into marriage with the free and full consent of the intending spouses, and to equality in and at the dissolution of marriage 7. the right to decide the number and spacing of one's children 8. the rights to information, as well as education 9. the rights to freedom of opinion and expression, and 10. the right to an effective remedy for violations of fundamental rights. The responsible exercise of human rights requires that all persons respect the rights of others. The application of existing human rights to sexuality and sexual health constitute sexual rights. Sexual rights protect all people's rights to fulfil and express their sexuality and enjoy sexual health, with due regard for the rights of others and within a framework of protection against discrimination." (WHO, 2006a, updated 2010)
} 
sexual, de escolher o parceiro, e de estabelecer de forma consensual o relacionamento, e as relações sexuais) e de decidir se quer ou não, e quando ter filhos. (PARKER, 2007a, p. 974).

Nos arranjos sociais da modernidade, o que se pode definir como uma verdadeira cidadania que observa os direitos à liberdade sexual guarda relação com a hipótese de quando é assegurado a todos o direito buscar satisfação, segurança e uma vida sexual correspondente ao direito de realização individual do sujeito. Para a construção dessa finalidade, é necessária mais do que a proteção dos direitos garantidos pela ordem estatal.

Uma vez que as noções da sexualidade são construídas principalmente nos seios das células sociais da cultura, da religião, e demais agentes não estatais: que modificam definições, a linguagem e formas de expressão da sexualidade. A responsabilidade é, por conseguinte, compartilhada para a garantia da cidadania, com base nos princípios da igualdade, liberdade e dignidade dos sujeitos humanos. Sobre a construção e desenvolvimento dos processos da cidadania: Democracia e cidadania são ideias centrais na pauta dos diversos movimentos sociais contemporâneos.

Por meio de sua articulação, uma gama variada de reivindicações tem sido levada adiante, abrangendo os mais diversos setores da vida individual e coletiva.

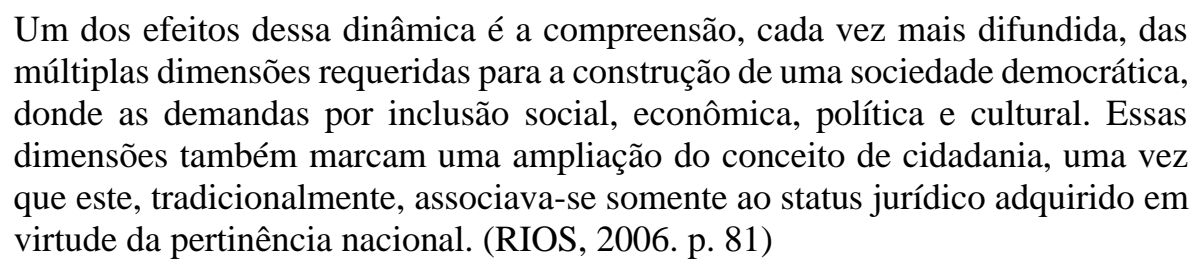

Embora reste claro que há um longo caminho até a cristalização das bases teóricas e pragmáticas na construção de ferramentas que permitam a exploração dos direitos sexuais como meio de promoção dos processos de cidadania, é igualmente evidente que a defesa da saúde sexual humana só é possível através da luta pelos direitos sexuais, como assim afirma Richard Parker: todavia estejamos distantes da realização plena do potencial dos direitos sexuais em qualquer das sociedades, é igualmente evidente que o percurso para a concretização da saúde sexual é sustentado pela luta pelos direitos sexuais. Sem que se esteja em bases firmes em uma concepção próxima aos direitos sexuais, a promoção da saúde sexual nunca poderá ser efetiva.

Igualmente importante é a forma como o campo das políticas públicas abordam a sexualidade, e conformam as possibilidades de realização da saúde sexual como plano amplo 
de comprometimento com a promoção dos valores humanos de dignidade. ${ }^{4}$ (PARKER, 2007, p. 947 - tradução livre).

Há na ampliação das vertentes de discursos e nas frentes de debates, o reconhecimento de que os direitos sexuais são importantes estratégias de ruptura e de promoção de valores humanos. As investigações sobre as possibilidades de intervenção na sexualidade e na saúde sexual marcam um importante passo na direção das conquistas de liberdade e nos planos de desenvolvimento, tanto no âmbito nacional, quanto nas esferas de integração regional e internacional.

Desse modo, o tema proposto importa aos estudos especializados em Direito Público e Direito Privado referentes à sexualidade humana, abrangendo de forma direta as garantias individuais e sociais do direito ao acesso à justiça, à justiça restaurativa, à tutela integral da pessoa humana, principalmente se tratando da intimidade e do livre desenvolvimento da personalidade.

Partindo-se da premissa da relevância e atualidade do estudo das hipóteses de controle social sobre a prática e exercício da sexualidade nas relações privadas através das novas ferramentas de interação social, o presente exame visa à sistematização do estado da arte sobre os direitos sexuais para a construção de um paradigma ético e democrático de tutela.

Avaliando-se, por fim, o estágio de desenvolvimento sobre a temática, buscando-se justificar a expressão "direitos sexuais democráticos", e definir os conteúdos componentes dessa construção jurídica. O estudo foi orientado com a perspectiva metodológica de promoção da aplicação do direito em respeito aos valores da dignidade da pessoa humana e das liberdades, tendo por principal preocupação o exercício das funções jurígenas de integração, criação e decisão.

Fez-se uso do método histórico de inventariação das principais construções paradigmáticas da ontognoseologia da sexualidade humana, para demonstração da multiplicidade de referenciais que informam os "direitos sexuais democráticos". Nesse sentido, a pesquisa apresentada filia-se à vertente jurídico-teórica, buscando acentuar os aspectos conceituais e doutrinários sobre o tema, adotando o tipo de investigação denominado jurídico-

\footnotetext{
4 "Although it is clear that we are still far from fully realizing the potential of sexual rights in any society, it is equally evident that the road to sexual health is underpinned by the struggle for sexual rights. Without being firmly rooted in a conception of and commitment to sexual rights, sexual health promotion can never be effective. Equally important, how the field of public health approaches sexuality shapes society's ability to realize sexual rights as part of a broader commitment to human dignity and worth. The current wave of public health research and intervention on sexuality and health marks an important step in this direction." (PARKER, 2007, p. 947)
} 
compreensivo, ao explorar a problemática que envolve a aplicação das teorias democráticas sobre o exercício da sexualidade, da liberdade e do desenvolvimento da personalidade.

\section{A EVOLUÇÃO HISTÓRICA DOS DIREITOS SEXUAIS NO ÂMBITO INTERNACIONAL: UMA PERSPECTIVA DE DIREITOS HUMANOS.}

A regulação internacional e a definição de parâmetros sobre os direitos sexuais facilitam o papel do Estado na efetivação das garantias individuais e de promoção dos processos de cidadania e formação integral do sujeito. É nesse sentido que se faz a necessidade de se historiar o desenvolvimento dos direitos sexuais no âmbito supranacional; e, a internacionalização do debate.

No âmbito internacional, a partir da Declaração Universal dos Direitos Humanos, adotada no ano de 1948, a comunidade internacional, por meio da Organização das Nações Unidas (ONU), vem firmando uma série de Convenções Internacionais nas quais são estabelecidos estatutos comuns de cooperação mútua e mecanismos de controle que garantam um elenco de direitos considerados básicos à vida digna, os direitos humanos.

A Conferência Internacional da ONU sobre População e Desenvolvimento (CIPD), realizada no Cairo, em 1994, conferiu papel primordial à saúde e aos direitos sexuais e aos direitos reprodutivos, ultrapassando os objetivos puramente demográficos, focalizando-se no desenvolvimento integral do ser humano. A CIPD provocou transformação profunda no debate populacional ao dar prioridade às questões dos direitos humanos. No capítulo VII, da Plataforma de Ação do Cairo, os direitos reprodutivos estão definidos da seguinte forma:

\footnotetext{
PLATAFORMA DE AÇÃO DO CAIRO Cap. VII: DIREITOS DE REPRODUÇÃO E SAÚDE REPRODUTIVA §7.3: Os direitos reprodutivos abrangem certos direitos humanos já reconhecidos em leis nacionais, em documentos internacionais sobre direitos humanos, em outros documentos consensuais. Esses direitos se ancoram no reconhecimento do direito básico de todo casal e de todo indivíduo de decidir livre e responsavelmente sobre o número, o espaçamento e a oportunidade de ter filhos e de ter a informação e os meios de assim o fazer, e o direito de gozar do mais elevado padrão de saúde sexual e reprodutiva. Inclui também seu direito de tomar decisões sobre a reprodução, livre de discriminação, coerção ou violência.
}

Na IV Conferência Mundial sobre a Mulher, realizada em Pequim, em 1995, reafirmamse os acordos estabelecidos no Cairo e avança-se na definição dos direitos reprodutivos e dos direitos sexuais como direitos humanos. Os direitos sexuais foram definidos de maneira mais 
autônoma em relação aos direitos reprodutivos. A igualdade sexual entre homens e mulheres e a liberdade de autodeterminação nas relações privadas, foram alçadas a condição de primazia nas políticas internacionais e de Estado no desenvolvimento dos processos de cidadania e da democratização das instituições de direito e promoção dos valores humanos.

Declaração e Plataforma de Ação da IV Conferência Mundial Sobre a Mulher Pequim, 1995 -

92. É preciso lograr que as mulheres possam exercer o direito a usufruir o mais elevado nível possível de saúde durante todo o seu ciclo vital, em igualdade de condições com os homens. As mulheres padecem de muitas das afecções de que padecem os homens, mas de maneira diferente. A incidência da pobreza e da dependência econômica da mulher, sua experiência com a violência, as atitudes negativas para com mulheres e meninas, a discriminação racial e outras formas de discriminação, o controle limitado que muitas mulheres exercem sobre sua vida sexual e reprodutiva, e sua falta de influência na tomada de decisões são realidades sociais que têm efeitos prejudiciais sobre sua saúde. A falta de alimento para meninas e mulheres e a distribuição desigual de alimentos no lar, o acesso inadequado à água potável, às facilidades sanitárias e ao combustível, sobretudo nas zonas rurais e nas zonas urbanas pobres, e as condições deficientes de moradia pesam excessivamente sobre a mulher e sua família e repercutem negativamente na sua saúde. A boa saúde é essencial para viver de forma produtiva e satisfatória, e é fundamental para o avanço das mulheres que tenham o direito de controlar todos os aspectos de sua saúde e, em especial, de sua própria fertilidade.

93. A discriminação contra as meninas no acesso aos serviços de nutrição e de atendimento à saúde, consequência frequente da preferência pelos filhos varões, põe em perigo sua saúde e bem-estar presentes e futuros. As condições que forçam as meninas ao casamento e à maternidade precoces, e que as submetem a práticas prejudiciais, como a mutilação genital, acarretam graves riscos para sua saúde. As adolescentes necessitam ter acesso a serviços de saúde e nutrição durante seu crescimento, porém, muitas vezes, esse acesso lhes é negado. A assistência social e o acesso à informação e aos serviços relativos à saúde sexual e reprodutiva das adolescentes continuam sendo inadequados ou totalmente inexistentes, e nem sempre se leva em consideração o direito das mulheres jovens à privacidade, à confidencialidade e ao respeito bem como à informação sobre as consequências de seus atos, a qual deve anteceder o consentimento. Do ponto de vista biológico e psicossocial, as adolescentes são mais vulneráveis do que os rapazes ao abuso sexual, à violência, à prostituição e às consequências das relações sexuais prematuras e sem proteção. A tendência a ter experiências sexuais em idade precoce, aliada à falta de informação e serviços, aumenta o risco de gravidez não desejada e em idade prematura, assim como de contrair o HIV e outras enfermidades transmitidas sexualmente, e de abortar em condições perigosas. A maternidade prematura continua sendo um obstáculo para o progresso educacional, econômico e social das mulheres em todo o mundo. Em geral, o casamento e a maternidade prematuros podem reduzir drasticamente as possibilidades de educação e de emprego das meninas e, provavelmente, prejudicar em longo prazo a qualidade de sua vida e da vida de seus filhos. Frequentemente, os jovens não são educados a respeitar a livre determinação da mulher e a compartilhar com ela as responsabilidades inerentes à sexualidade e à reprodução. 96. Os direitos humanos das mulheres incluem os seus direitos a ter 
controle sobre as questões relativas à sua sexualidade, inclusive sua saúde sexual e reprodutiva, e a decidir livremente a respeito dessas questões, livres de coerção, discriminação e violência. A igualdade entre mulheres e homens no tocante às relações sexuais e à reprodução, inclusive o pleno respeito à integridade da pessoa humana, exige o respeito mútuo, o consentimento e a responsabilidade comum pelo comportamento sexual e suas consequências.

Nessas Conferências, os governos de vários países, entre os quais se inclui o Brasil, assumiram o compromisso de basear nos direitos sexuais e nos direitos reprodutivos todas as políticas e os programas nacionais dedicados à população e ao desenvolvimento humano, inclusive os programas de planejamento familiar. Ademais, os Programas e as Plataformas de Ação propostos nas conferências acima citadas enfatizaram a necessidade de promover-se a igualdade entre homens e mulheres, como requisito essencial para a conquista de melhores condições de saúde e de qualidade de vida, e de promover-se, de igual modo, o efetivo envolvimento e corresponsabilidade dos homens nas questões referentes à saúde sexual e reprodutiva. Exortam, também, os governos a propiciarem aos adolescentes informações e serviços adequados para atenção à sua saúde sexual e reprodutiva, dentre outras providências.

Em 1997, a Associação Mundial para a Saúde Sexual - The World Association for Sexual Health (WAS) - proclamou no $13^{\circ}$ Congresso de Sexologia na cidade de Valência, e, ratificou com ampla aprovação, no ano de 1999, na Assembleia de Hong Kong - a Declaração dos Direitos Sexuais, a qual inclui - após revisões e reafirmação em 2008 (Declaration: Sexual Health for the Millenium), 16 (dezesseis) espécies dos direitos sexuais. Os quais se passam a considerar em seguida.

O direito à igualdade e não discriminação: afirmando que todos têm o direito de gozar dos direitos albergados pela declaração de direitos, sem distinção de qualquer espécie como raça, etnia, cor, sexo, língua, religião, opinião política, nacionalidade, origem, propriedades, nascimento, deficiência, idade, status marital e familiar, orientação sexual, identidade de gênero e expressão, condição de saúde, status econômicos ou outro status.

O direito à vida, à liberdade e à segurança: afirmando que o sujeito não pode sofrer ameaça, limitação ou ser subtraído de seu direito sexual. Isso inclui o direito à livre orientação sexual e a práticas dos comportamentos sexuais consentidos, à liberdade de gênero e de expressão, e acesso aos serviços relacionados à saúde sexual e reprodutiva.

O direito à autonomia e à integridade física: como o direito a ter controle e decidir livremente sobre os assuntos referentes à sexualidade e ao próprio corpo. Incluindo as escolhas comportamentais sobre o sexo, práticas, parceiros e relacionamentos, sempre tendo por 
limitação o direito do outro. A exigência das escolhas esclarecidas fundamentadas pelo consentimento informado referente à tratamentos, intervenções, terapias, testes, cirurgias e pesquisas clínicas das ciências da saúde.

O direito a ser livre de tortura, tratamento cruel e desumano, ou degradante e punição: como o direito de ser livre de práticas tradicionais como: esterilização forçada, contracepção involuntária, aborto, ou outras formas de tortura, crueldade, e tratamento degradante, em virtude de comportamento sexual diverso, orientação sexual, questão de gênero, ou expressão.

O direito a estar livre de todas as formas de violência e coação: incluindo a proibição do estupro, do abuso sexual, da ameaça sexual, bullying, exploração sexual, escravidão, tráfico para a finalidade da exploração sexual, teste de virgindade, ou qualquer violência relacionada à repressão do comportamento sexual.

O direito à privacidade: afirmando que todos têm o direito à privacidade relacionado à própria sexualidade, à vida sexual, às escolhas referentes ao próprio corpo e às relações privadas consensuais, sem que haja intromissão e interferências arbitrárias. Aqui se inclui o direito a controlar o fluxo das informações relativas à intimidade sexual ao conhecimento de terceiros.

O direito ao mais elevado grau do standard da saúde, incluindo a saúde sexual/ com a possibilidade de gozar de uma vida sexual prazerosa, satisfativa e segura: garantido ao sujeito o acesso aos meios de qualidade e adequação para cuidar dos fatores que possam influenciar na saúde sexual do ser humano. O direito de usufruir dos benefícios dos progressos científicos: afirmado a promoção axiológica-normativa da distribuição do avanço da lex artis como um bem difuso, e de titularidade coletiva; fora da apropriação pelo interesse egoístico, e de vocação ao melhoramento da condição humana.

$\mathrm{O}$ direito à informação: como fundamentalidade para o exercício do direito à sexualidade, vedando as práticas de censura de conteúdos indispensáveis para o firmamento das bases de responsabilidade do sujeito quando da prática do sexo. Para tanto, a informação não pode ser reduzida, limitada ou formulada ilegitimamente.

O direito à educação sexual: como indispensável à formação humana para o sexo, devendo observar a adequação quanto à idade, o rigor científico, as adaptações culturais, e baseada sempre na defesa dos direitos humanos, igualdade de gênero, e aproximação positiva de todas as possíveis finalidades do sexo (reprodução, prazer, realização pessoal, expressão...)

O direito a constituir, formar, dissolver o casamento ou qualquer tipo equiparável, ou relações baseadas na igualdade e no consentimento livre dos envolvidos: garantindo o 
equilíbrio da vontade dos parceiros em constituir, permanecer e pôr término a relacionamentos: conferindo-se aos sujeitos da relação o meu grau de autodeterminação e competências para definir suas situações de fato e de direitos.

O direito a escolher livremente se deseja ter filhos, o número e o intervalo das gestações, assim como ter informações adequadas sobre o planejamento familiar: o que inclui o acesso aos métodos contraceptivos, pré-natal, às tecnologias de reprodução, fertilidade, adoção, entre outros.

O direito à liberdade de expressão, opinião e pensamento: assegurando ao sujeito as possibilidades de expor os pensamentos sobre a sexualidade, sobre comunicações e comportamentos, desde que observados os limites dos direitos dos outros.

O direito à liberdade de associação: para a discussão, advocacy e exercício das práticas de governança referente aos direitos sexuais e à saúde sexual. O direito de participar da vida pública e política: como o direito de participar livremente e de forma efetiva dos processos de tomada de decisão e contribuição para a vida em sociedade, aditando as ações civis, econômicas, sociais, culturais, política, a todos os níveis de organização.

O direito ao acesso à justiça, aos remédios e indenização por lesões aos direitos sexuais: o acesso à justiça é condição fundamental para o exercício efetivo da sexualidade, sem o qual é impossível falar em liberdade e dignidade sexual. É um direitocondição que exige meios efetivos, adequados, acessíveis, apropriados de medidas legislativas, judiciais, educativas sobre as possibilidades de defesa. O acesso à justiça alberga ainda o direito à restituição, compensação, reabilitação, satisfação, garantia e não reincidência da conduta lesiva.

O conjunto de direitos descritos pela Associação Mundial para a Saúde Sexual (WAS, 2008), influenciou diretamente a definição dos direitos sexuais adotada pela Organização Mundial de Saúde, e ademais, alterou sobremaneira a condução das discussões internacionais sobre a matéria, posto que a sistematização possibilitou o diálogo d'antes setorizado e segmentado pelas agendas de grupos de direitos específicos.

Nesse sentido, há de se reconhecer que, em um primeiro momento histórico, os direitos sexuais figuraram na pauta das discussões internacionais sobre direitos humanos e políticas de desenvolvimento tangenciando o debate das temáticas relativas ao direito à vida, à saúde, à igualdade e não-discriminação, à integridade corporal e à proteção contra violência, ao trabalho e à educação. Esses direitos, inscritos na Declaração Universal dos Direitos Humanos, no Pacto Internacional de Direitos Civis e Políticos, no Pacto Internacional dos Direitos Econômicos, Sociais e Culturais e na Convenção Americana de Direitos Humanos, observaram também as 
preocupações específicas com a reprodução e, nesse contexto, a condição feminina. Há de se observar, todavia, que nas últimas duas décadas, ocorreu uma viragem sobre a relação dos direitos humanos, e a sexualidade passou a ser observada de forma autônoma.

A questão não é mais o debate sobre como os direitos humanos se relacionariam com a sexualidade, mas ao invés: os debates se voltaram para o enfrentamento de problemas de ordem prática, a se considerar em que situações os direitos sexuais mereceriam tutela, em que termos deveriam ser reconhecidos, quais os seus titulares, a que finalidade cumpririam, além da definição de seus aspectos fundamentais e seus limites.

Em meados dos anos 2000, Robert Archer apontou o marco da justaposição e consequente articulação dos debates até o momento desconexos sobre as questões afirmativas dos direitos das mulheres e violência, da pauta LGBT, dos direitos das crianças e da assistência à reprodução humana, pela unificação por meio da alcunha dos "direitos sexuais".

A locução unificou as ações de governança e os discursos acadêmicos sobre a expressão da sexualidade como corolário dos direitos humanos e da dignidade. E logo, promoveu ações integrativas para o enfrentamento de questões comuns, e respostas aos desafios que se apresentavam: como a questão da globalização dos sistemas de informação, e a necessidade de regulação de comportamentos na rede. (ARCHER, 2009, p. 45).

A construção dos significantes dos "direitos sexuais" encontrou resistência nos segmentos mais conservadores da aldeia global, que não admitiram no termo a porosidade que colocava na mesma categoria o sexo, as crianças, os homens, as mulheres, as comunidades LGBT, o que na tese defendida representaria a incoerência de pôr em mesmo ambiente interesses "tão contrários"5.

\footnotetext{
${ }^{5}$ Family Watch International: Policy Brief. "Sexual rights" is a controversial, elastic term that is used to promote a number of controversial rights relating to human sexuality. It is the Trojan horse of the sexual rights movement. Fortunately, every time "sexual rights" in any grammatical formulation has been proposed by liberal countries during negotiations, it has been rejected - for good reason. There is no international consensus on the definition of the term. When a definition is called for by a Member State during negotiations, the only response is that there isn't a definition. While the term "reproductive rights" garnered an explanation in ICPD,1 there is no such explanation or definition for "sexual rights," which is why the use of this term in official UN documents is so dangerous. A disturbing trend occurring with increasing frequency within the United Nations system is the appearance of the term "sexual rights"2 in UN publications that have not been negotiated by UN Member States. Since sexual rights advocates know they cannot get the term "sexual rights" adopted in documents and resolutions that are negotiated transparently by UN Member States, they seek to get UN agencies and experts to include "sexual rights" in reports they publish instead. Then they try to convince UN Member States to endorse reports in UN resolutions, without Member States fully realizing or understanding the controversial elements they contain. Although UN Member States have not arrived at consensus with regard to the definition of "sexual rights," some UN agencies, including UNFPA and WHO, and some ECOSOCaccredited NGOs have developed their own definition of "sexual rights." These definitions provide a glimpse of the potential damage that would result to societies, families, and individuals-especially children-throughout the world if the term is allowed in
} 
Em janeiro de 2002, a Organização Mundial de Saúde adotou uma "definição de trabalho" para os direitos sexuais, apresentando como disclaimer a afirmação que tal definição não representaria uma posição oficial da entidade. Seria apenas uma forma de instrumentalização dos debates, por meio de definições e consultas à experts nas áreas de aderência, refletindo ademais uma compreensão globalizante dos consensos internacionais desenvolvidos nas lidas dos Programas de Ações do Cairo e de Pequim.

No Brasil, o termo é aceito no programa das políticas públicas nacionais editadas pelo Ministério da Saúde, e é tratado como política prioritária. Exemplifica-se a aceitação com as Normas e Manuais Técnicos editados no ano de 2005 pelo Ministério da Saúde sobre as providências dos "Direitos Sexuais e Reprodutivos: uma prioridade do Governo". O tratamento internacional sobre a matéria é disforme.

Apenas em 2015, os Estados Unidos anunciaram que passariam a usar "direitos sexuais" para se referir nos debates sobre a sexualidade humana nas agendas sobre direitos humanos e desenvolvimento internacional. O pronunciamento foi no sentido de reconhecer na expressão a força de defesa do direito de ter controle sobre a própria sexualidade e de exercer livremente e de forma responsável todas as questões referentes ao sexo, incluindo a autodeterminação reprodutiva, livre de coerção, discriminação e violência. ${ }^{6}$

O comunicado oficial se deu após a reunião da cúpula da ONU para a revisão das metas para o milênio, quando se definiu na agenda internacional o compromisso com a igualdade de gênero como pressuposto para o desenvolvimento e diminuição das desigualdades entre os Estados em desenvolvimento.

A nova agenda tem como objetivo a universalização dos direitos sexuais e reprodutivos até o ano de 2030:

ORGANIZAÇÃO DAS NAÇÕES UNIDAS A/RES/70/1 - Transformando Nosso Mundo: A Agenda 2030 para o Desenvolvimento Sustentável

\section{A NOVA AGENDA}

26. Para promover a saúde física e mental e o bem-estar, e para aumentar a expectativa de vida para todos, temos de alcançar a cobertura universal de saúde e acesso a cuidados de saúde de qualidade. Ninguém deve ser deixado para trás. Comprometemo-nos a acelerar os progressos alcançados até o momento na redução da mortalidade neonatal, infantil e materna, dando um fim a todas essas

documents directly, and even if the term is allowed indirectly, through references to outside documents in which the term appears.

${ }^{6}$ On one level, it's symbolic. It also sends a signal to the global community that sexual and reproductive health and rights are a part of the global development agenda.(...) This is the United States catching up with the rest of the world." (SIPPLE, 2015). ANNA, Cara. 
mortes evitáveis antes de 2030. Estamos empenhados em garantir o acesso universal aos serviços de saúde sexual e reprodutiva, inclusive para o planeamento familiar, para a informação e para a educação. Iremos igualmente acelerar o ritmo dos progressos realizados na luta contra a malária, HIV/AIDS, tuberculose, hepatite, ebola e outras doenças e epidemias transmissíveis, incluindo a abordagem em relação à crescente resistência antimicrobiana e o problema das doenças negligenciadas que afetam os países em desenvolvimento. Estamos comprometidos com a prevenção e o tratamento de doenças não transmissíveis, incluindo distúrbios de comportamento, de desenvolvimento e neurológicas, que constituem um grande desafio para o desenvolvimento sustentável.

\section{Objetivo}

3. Assegurar uma vida saudável e promover o bem-estar para todos, em todas as idades

3.7 Até 2030, assegurar o acesso universal aos serviços de saúde sexual e reprodutiva, incluindo o planejamento familiar, informação e educação, bem como a integração da saúde reprodutiva em estratégias e programas nacionais. 3.8 Atingir a cobertura universal de saúde, incluindo a proteção do risco financeiro, o acesso a serviços de saúde essenciais de qualidade e o acesso a medicamentos e vacinas essenciais seguros, eficazes, de qualidade e a preços acessíveis para todos.

Desse modo, os direitos sexuais vêm se consolidando no panorama internacional dos direitos humanos, na definição de metas de desenvolvimento e uniformização das políticas de promoção dos valores humanos, na construção de um paradigma de convenção sobre o sexo, a Liberdade e dignidade do ser humano.

\section{A PROTEÇÃo CONSTITUCIONAL DA LIBERDADE, IGUALDADE E INTIMIDADE COMO FUNDAMENTOS AXIOLÓGICO-NORMATIVOS DOS DIREITOS SEXUAIS DA PESSOA HUMANA: UM EXAME DO ORDENAMENTO CONSTITUCIONAL BRASILEIRO.}

A construção democrática dos processos de cidadania e de promoção dos direitos humanos em relação ao sexo depende diretamente da sustentação formal e funcional dos direitos da sexualidade, como forma de defesa e de prevenção dos perigos da perpetuação de estigmas sociais, das violências e dos abusos registrados nas representações sociais estratificadas.

O debate importa não só às parcelas das sociedades que lutam pelo reconhecimento identitário, mas - de uma forma geral -, a defesa de fundamentos axiológico-normativos dos direitos sexuais da pessoa humana representa a pedra angular para as estratégias de desenvolvimento dos valores e do progresso social. 
Cuida-se, portanto, do desafio em se elaborar uma construção dos direitos da sexualidade que tente evitar a perpetuação das desigualdades de gênero, da objetificação do sexo, da via sexual para o cometimento de violências, com a finalidade de se informar que, através dos princípios da liberdade, da igualdade e da intimidade, há a possibilidade de estruturação de mecanismos de defesa que sejam eficazes para àqueles que reclamam proteção.

A fundamentalidade dos direitos e garantias constitucionais inauguraram na legalidade constitucional brasileira novas formas de se interpretar o fenômeno jurídico, angulando a atividade hermenêutica com a finalidade da tutela integral da pessoa humana.

Esta considerada em sua ampla competência de sujeito destinatário da tutela jurídica, o que faz exigir do intérprete a busca por soluções que contemplem a individualidade e o resultado útil e eficaz da tutela.

Há, portanto, através dos pontos de partida dos fundamentos axiológico-normativos informados pelos princípios constitucionais da igualdade, da intimidade e da liberdade, a formatação de um sistema de tutela dos direitos individuais e coletivos que respaldam o desenvolvimento das teorias sobre a existência e aplicação dos direitos sexuais na legalidade constitucional brasileira.

Nesse sentido, o que se propõe é uma revisão técnica e descritiva das formas de aplicação dos pressupostos axiológico-normativos constitucionais que fundamentam os direitos sexuais na realidade do ordenamento jurídico brasileiro, com o foco nas garantias individuais que se prestam à defesa das vítimas de violações aos direitos sexuais.

\subsection{DOS DIREITOS E DAS GARANTIAS INDIVIDUAIS}

Há de se reconhecer que no âmbito das relações privadas, nas quais se desenvolvem as atividades sexuais, existe o fator potencial do conflito de liberdades e garantias constitucionais. Pondo-se em linha de colisão: de um lado, as garantias de liberdade, igualdade (material) e intimidade; e de outro, as liberdades relacionadas às garantias do discurso e da liberdade de expressão.

Exemplifique-se com a exposição nos contextos privados (círculos de amizade) ou públicos (fóruns de discussões) dos fatos ocorridos na intimidade da relação sexual, quando os parceiros não firmaram expressamente os limites das expectativas de privacidade, ou de confiança quanto ao sigilo. Ou ainda, sobre a hipótese de compartilhamento de material de cunho sexual produzido por terceiros, com a intenção de notícia do acontecimento. Sobre a 
relação problemática dos direitos sexuais e sua compatibilização com demais direitos, liberdades e garantias, faz-se mister as seguintes considerações da técnica.

Os direitos e garantias individuais, sem embargo de estarem contemplados sistematicamente no art. $5^{\circ}$ da Constituição Federal, não se restringem a ele, sendo possível a identificação de outros direitos dessa espécie, quando da interpretação sistemática de todo conjunto axiológico-normativo de direitos constitucionais.

Dessa forma, para a determinação do conteúdo de fundamentalidade de um direito, há de se considerar o âmbito de proteção do conteúdo inicialmente identificado; e, em um segundo momento, a necessidade de se conciliar o direito fundamental com outros direitos e bens constitucionalmente tutelados. A sistematização das restrições tem como base a teoria estruturante dos direitos fundamentais como regras de dever ser, e também, por vezes como princípios (teoria da dualidade). (NOVELINO, 2013, p. 458 et seq.).

Para a definição do conteúdo de direito efetivamente tutelado, devem ser aplicadas ferramentas metodológicas de sopesamento de razões e contra-fatos, e ainda o postulado da proporcionalidade, quando se tratar de análise da constitucionalidade de uma medida restritiva de direitos. Os direitos fundamentais devem ser analisados em um conjunto de integralidade (vida, igualdade, privacidade, liberdade e propriedade), independentemente do seu conteúdo nuclear definido por formulações específicas: uma vez que essas são insuficientes para garantir a racionalidade das decisões em casos difíceis.

Para a solução integrativa e de criação de normas de partida e de chegada para a solução de casos complexos, há de se reconhecer que na normatividade constitucional, os direitos fundamentais funcionam como normas de caráter duplo, capazes de reunir em si, níveis de regra e de princípio. Nesse sentido, por terem sido elencados como conteúdos essenciais na construção do direito democrático à sexualidade: a liberdade, a igualdade e a intimidade passam a ser analisadas nessa seção, mais detidamente, quanto ao conteúdo essencial e seus limites, com fins de balizamento das estruturas da tutela dos direitos sexuais da pessoa humana.

\subsection{DIREITOS DE LIBERDADE}

Ingo Wolfgang Sarlet afirma que o elemento nuclear da noção de dignidade da pessoa humana continua sendo reconduzido primordialmente à matriz kantiana, centrando-se, portanto, na autonomia e no direito de autodeterminação da pessoa (de cada pessoa), ou seja, 
do indivíduo conformador de si próprio e da sua vida segundo o seu próprio projeto espiritual (SARLET, 2010, p. 53).

Importa ter presente a circunstância de que esta liberdade - baseada na autonomia privada - é considerada em abstrato, como sendo a capacidade potencial que cada ser humano tem de autodeterminar sua conduta, não dependendo da sua efetiva realização no caso da pessoa em concreto.

De tal sorte que também as pessoas consideradas absolutamente incapazes possuem exatamente a mesma dignidade que qualquer outro ser humano física ou mentalmente capaz (ibid, p. 54). Todavia, há de se esclarecer que não há equivalência entre o conteúdo da liberdade e da dignidade como valores axiológico-normativos.

Há uma intrínseca relação entre as noções, haja vista tratar a liberdade - assim como os demais direitos fundamentais - de uma exigência condicional da dignidade humana. Desse modo, as garantias do direito da liberdade consistem na prerrogativa fundamental que investe o ser humano de um poder de autodeterminação e realização do seu próprio projeto de individualidade (BARROSO, 2009. p 12).

No padrão da normatividade constitucional brasileiro, segundo a classificação de Dirley da Cunha Júnior (2009), o direito à liberdade é garantido pela: a) liberdade de ação; b) liberdade de locomoção; c) a liberdade de opinião ou pensamento; d) a liberdade de expressão de atividade intelectual, artística, científica e de comunicação; e) liberdade de informação; f) liberdade de consciência e crença; g) a liberdade de reunião; h) a liberdade de associação; e i) a liberdade de opção profissional. Em observância ao recorte do tema desta análise, passa-se ao exame descritivo apenas das garantias: 1) da liberdade de ação; 2) liberdade de opinião e pensamento; e 3) da liberdade de expressão de atividade intelectual, artística, científica e de comunicação. Primeiramente, a liberdade de ação é prevista pelo art. $5^{\circ}$, II, da Constituição Federal, segundo o qual "ninguém será obrigado a fazer ou deixar de fazer alguma coisa senão em virtude da lei”.

De tal dispositivo extrai-se o conteúdo da garantia positiva de se agir segundo o padrão da legalidade, e a negativa de que qualquer limitação ao patrimônio jurídico individual deva ocorrer por força do princípio também da legalidade estrita. A lei é, por conseguinte, o único instrumento autorizado pela Constituição para restringir a liberdade de ação das pessoas.

A liberdade de pensamento ou de expor livremente as opiniões é a garantia do Estado democrático de direito de ser livre o sujeito para exprimir o que pensa - livre de qualquer censura de natureza ideológica, política e artística (art. $220, \S 2^{\circ}$ ), através de qualquer forma, 
processo ou veículo. Inclui a liberdade de expressar juízos, conceitos, conclusões e valores sobre determinações específicas, tendo como a limitação - por força regra de igual hierarquia - da vedação do anonimato (art. $5^{\circ}$, IV).

O contrabalanço do direito à livre manifestação do pensamento é a garantia constitucional do direito de resposta concedido àquele que se sentiu ofendido ou atingido pela opinião de outrem. A resposta é garantida pela igual proporção do agravo, além de ter a parte ofendida, direito à indenização por danos materiais, morais ou à imagem. (art. 5º $\mathrm{V}$ da CRFB/88: é assegurado o direito de resposta, proporcional ao agravo, além da indenização por dano material, moral ou à imagem).

A liberdade de expressão de atividade intelectual, artística, científica e de comunicação é prevista no art $5^{\circ}$, IX, da Constituição: "é livre a expressão da atividade intelectual, artística, científica e de comunicação, independentemente de censura ou licença”. Trata-se de uma decorrência lógica do direito à liberdade de expressão do pensamento; o traço distintivo é de nessa espécie, é garantida liberdade do indivíduo de expor suas percepções sensíveis, emocionais e criativas: incluindo-se as formas como o ser humano retrata experiências vividas ou imaginadas, por meio da música, do cinema, da fotografia, dentre tantos outros (CUNHA JUNIOR, 2009. p. 54).

Nesse âmbito de proteção, a Constituição também dispensa tutela especial aos autores das manifestações intelectuais, artísticas e científicas. No art. $5^{\circ}, \mathrm{XXVII}$, reconhece aos autores o direito exclusivo de utilização, publicação ou reprodução de suas obras, transmissível aos herdeiros pelo tempo que a lei fixar (referência ao desenvolvimento da regulamentação infraconstitucional do direito autoral).

Já no inciso XXVIII, assegura-se, a proteção às participações individuais em obras coletivas e à reprodução da imagem e voz humanas, inclusive nas atividades desportivas; e b) o direito de fiscalização do aproveitamento econômico das obras que criarem ou de que participarem aos criadores, aos intérpretes e às respectivas representações sindicais e associativas.

Depreende-se da análise do conteúdo das liberdades que há uma ampla proteção da liberdade de ação e das liberdades comunicativas das experiências sensoriais e imaginativas dos particulares, na medida em que o exercício seja realizado com a responsabilidade da consideração mútua dos interesses de todos envolvidos. Há na liberdade de expressão sexual a possibilidade do consentimento para que os atos se tornem públicos e que representem uma manifestação legítima de cultura, de hábitos de vida, ou de liberdade. 
O contraponto é que os excessos que violem os limites de tolerância do sujeito, seja interpretado como conduta abusiva e, portanto, ilegítima, devendo o sujeito ativo ser responsável pela reparação dos danos materiais e imateriais causados à vítima.

\subsection{DIREITOS DE IGUALDADE}

A igualdade informa e sustenta o princípio maior da dignidade da pessoa humana, partindo-se da premissa amplamente aceita de que a dignidade independe das circunstâncias concretas, já que é inerente a toda e qualquer pessoa humana, visto que, em princípio, todos "mesmo o maior dos criminosos" - são iguais em dignidade, no sentido de serem reconhecidos como pessoas - ainda que não se portem de forma igualmente digna nas suas relações com seus semelhantes, inclusive consigo mesmos. (SARLET, 2010, p. 52).

Assim, mesmo que se possa compreender a dignidade da pessoa humana como forma de comportamento, por constituir atributos intrínseco da pessoa humana e expressar o seu valor absoluto, é que a dignidade de todas as pessoas, mesmo aquelas que cometem as ações mais odiosas e infames, não poderá ser objeto de desconsideração. Não existe hipótese de desconsideração da dignidade da pessoa humana no direito brasileiro; não importando o grau de reprovabilidade e censura social que a conduta em exame possa receber.

Nesse sentido, o elemento de cauda das violações da intimidade sexual, ainda que sejam levados em consideração para o sopesamento das medidas e cautelas, nunca pode ser bastante para sustentar atos de repreensão que importem na desconsideração da dignidade da pessoa humana. No mesmo sentido é o entendimento referendado pelo art. $1^{\circ}$ e $2^{\circ}$ da Declaração Universal da ONU, de 1948, segundo a qual: Artigo 1 Todos os seres humanos nascem livres e iguais em dignidade e direitos.

Dotados de razão e consciência, devem agir uns com os outros em espírito de fraternidade" Artigo 2 I) Todo o homem tem capacidade para gozar os direitos e as liberdades estabelecidos nesta Declaração sem distinção de qualquer espécie, seja de raça, cor, sexo, língua, religião, opinião política ou de outra natureza, origem nacional ou social, riqueza, nascimento, ou qualquer outra condição. II) Não será também feita nenhuma distinção fundada na condição política, jurídica ou internacional do país ou território a que pertença uma pessoa, 
quer se trate de um território independente, sob tutela, sem governo próprio, quer sujeito a qualquer outra limitação de soberania.

O padrão axiológico-normativo do direito à igualdade é sustentado pelo fato de os seres humanos, todos eles, serem dotados de razão e consciência: constituindo esse o fator de denominador comum a todos os homens, expressando em que consiste sua igualdade (MIRANDA, 2000, p.183).

E é nessa igualdade material que se reconhece a essência e fundamento do direito a ser diferente, e seguir padrões de condutas que - dentro da consideração dos limites de tolerância da ordem social - representem o projeto individual da personalidade do sujeito. A igualdade passa a ser considerada como um arranjo denso de possibilidades de exercício e gozo de direitos: há um conteúdo material na igualdade. $\mathrm{O}$ direito à igualdade material garante proteção à dignidade da pessoa humana, abrangendo as diferenças étnicas, filosóficas, raciais, culturais, religiosas, sexuais, enfim, à diversidade. $\mathrm{O}$ direito à diferença: o direito à diferença para ser $\mathrm{o}$ contraposto do direito à igualdade.

É, na realidade, com este, um dos componentes de base do direito geral da personalidade, não se compreendendo um sem o outro. Cada ser humano é diferente de todos os outros, e é esta diversidade que enriquece a Humanidade. O direito à igualdade, entendido como direito à não discriminação. Existe no campo público, normalmente perante o Estado. $\mathrm{Na}$ esfera privada, cada ser humano tem o direito de ter (ser) as suas opiniões e de as praticar; de se cercar de quem bem entenda. Além de poder exprimir as suas ideias pelos meios de seu alcance. (DE CAMPOS, 1992, p. 82) Quanto mais se respeita a diferença, mais se preserva a igualdade.

Desse modo, o direito à igualdade é a garantia de que todos têm de ser tratados igualmente na medida de em que se igualem, e desigualmente na medida em que se desigualem, quer perante a ordem jurídica (igualdade formal), quer perante a oportunidade de acesso aos bens da vida (igualdade material).

Trata-se de um postulado básico da democracia, pois significa que todos merecem a mesma consideração, sendo defeso qualquer tipo de discriminação, perseguição ou diminuição de qualquer gênero, como também é vedado o favorecimento por privilégio de qualquer espécie. (MENDES, 1977, p. 112). “O princípio em tela interdita o tratamento desigual às pessoas iguais e tratamento igual às pessoas desiguais" afirma Dirley da Cunha Júnior, que em esforço de sistematização, elencou as hipóteses da normativa constitucional que referendam o princípio da igualdade: 
A Constituição de 1988 preocupou-se tanta em assegurar a igualdade de todos, que prescreveu, em várias disposições de seu texto, que é objetivo fundamental do Estado "promover o bem de todos, sem preceitos de origem, raça, sexo, cor, idade e quaisquer outras formas de discriminação" (art. $3^{\circ}$, IV); que "todos são iguais perante a lei, sem distinções de qualquer natureza, garantindo-se (...) a inviolabilidade do direito (...) à igualdade" (caput do art. $5^{\circ}$ ); que "homens e mulheres são iguais em direitos e obrigações" (art. 5, I); que "a lei punirá qualquer discriminação atentatória aos direitos e liberdades fundamentais" (art. $\left.5^{\circ}, \mathrm{XLI}\right)$; que "a prática do racismo constitui crime inafiançável e imprescritível, sujeito à pena de reclusão, nos termos da lei" (art. 5, XLII); a "proibição de diferença de salários, de exercício de funções e de critério de admissão por motivo de sexo, idade, cor ou estado civil" (art. $7^{\circ}, \mathrm{XXX}$ ); a "proibição de qualquer discriminação no tocante a salário e critérios de admissão do trabalhador portador de deficiência (art. $7^{\circ}, \mathrm{XXXI}$ ); a proibição de distribuição entre trabalho manual, técnico e intelectual ou entre os profissionais respectivos (art. $7^{\circ}, \mathrm{XXXII}$ ); a "igualdade de direitos entre trabalhador com vínculos empregatício permanente

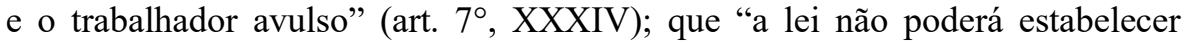
distinção entre brasileiros natos e naturalizados, salvo nos casos previstos nesta Constituição (art. 12, § $2^{\circ}$ ); que é vedado à União, aos Estados, ao Distrito Federal e aos Município "criar distinções entre brasileiros ou preferências entre si (art. 19, III); que "a remuneração entre servidores públicos e o subsídio de que trata o $\S 4^{\circ}$ do art. 39 somente poderão ser fixados ou alterados por lei específica, (...) assegurada revisão geral anual, sempre na mesma data e sem distinção de índices" (art.37, X); que "é vedada a vinculação ou equiparação de quaisquer espécies remuneratórias para o efeito de remuneração pessoal do servidor público" art. 37 , XIII; que "é vedado à União, aos Estados, ao Distrito Federal e ao Municípios "instituir tratamento desigual entre contribuintes que se encontrem em situação equivalente, proibida qualquer distinção em razão de ocupação profissional ou função por ele exercida, independente da denominação jurídica dos rendimentos, títulos ou direitos (art. 150, II); que é vedado à União "instituir tributo que não seja uniforme em todo o território nacional ou que implique distinção ou preferência em relação a Estado, ao Distrito Federal ou a Município, em detrimento de outro, admitida a concessão de incentivos fiscais destinados a promover o equilíbrio do desenvolvimento sócio-econômico entre as diferentes regiões do país" (art. 151, I); e que é "vedado aos Estados, ao Distrito Federal e aos Municípios estabelecer diferença tributária entre bens e serviços de qualquer natureza, em razão de sua procedência ou destino" (DA CUNHA JÚNIOR, 2009, p. 658-659)

São espécies da normatividade constitucional que garantem, portanto, o direito do indivíduo à igualdade na lei: que significa que nas normas jurídicas não pode haver distinções que não sejam autorizadas pela própria Constituição, impondo o dever do legislador de agir conformemente, referendando sempre a igualdade no estabelecimento do referencial jurídico das relações. A dois, estipula-se a igualdade perante a lei segundo a qual se deve aplicar igualmente a lei, mesmo que crie uma situação fática de desigualdade.

Essa vertente das espécies prevista visa à vinculação dos aplicadores, que não poderão sujeitar o exame do caso concreto à critérios que ensejem tratamento seletivo ou discriminatório. A lei não deve ser fonte de privilégios ou perseguições, mas instrumento 
regulador da vida social que necessita tratar equivalentemente os cidadãos. Este é o conteúdo político-axiológico absorvido pelo princípio da isonomia e juridicizado pelos textos constitucionais em geral, ou de todo modo assimilado pelos sistemas normativos vigentes. (MELLO, 2006, p.10)

No contexto atual, respeitar as diferenças e regular as relações privadas com inspiração na igualdade, tem tanto o sentido de igualar os poderes sociais, quanto o sentido de proibir ou coibir qualquer tipo de discriminação. $\mathrm{O}$ fato de a lei conter algum fator discriminatório, qualquer que seja ele, não é suficiente para se considerar ofendida a cláusula de igualdade. As leis podem discriminar. Contudo, as discriminações legais, só consubstanciam a defesa da igualdade formal ou material - se observarem o requisito da pertinência lógica entre a distinção inserida na lei e o tratamento distintivo dela consequente (MELLO, 2006, p. 11).

De modo que para se examinar a ofensa ao dogma da igualdade, tem-se que considerar o parâmetro adotado como critério para discriminação; confrontado em seguida como a justificativa racional para o tratamento desigual. Significa dizer que ao se anotar o dado social de que a exposição da intimidade sexual é um dado de prevalência quando se classifica os ofendidos por gênero, poder-se-ia defender a conclusão de que tutelas específicas e políticas públicas de afirmação seriam justificadas.

O tratamento desigual com base na lei é legítimo para a garantia da igualdade material, e da promoção das diferenças criadas com base nas identidades. Ainda sobre a diferenciação entre liberdade "formal" e liberdade "material" - ou, liberdade como abstração e liberdade como efetividade -, Carlos Eduardo Pianovski Ruzyk afirma que a expressão da liberdade em seu aspecto formal foi a marca da tradição civilista da vinculação da propriedade e liberdade na formação do capitalismo, no auge do pensamento liberal dos Séculos XVII a XIX.

Faz-se aqui referência à obra de Paolo Grossi - A propriedade e as propriedades na oficina do historiador (2006). Já por liberdade como efetividade, o autor afirma a denotação da possibilidade efetiva de se fazer o que se valoriza - necessariamente - é condicionada a se deter um conjunto mínimo de capacidades. O conceito incorpora, no âmbito das próprias liberdades, as condições materiais e subjetivas de exercício da liberdade formal. (RUZYK, 2011, p. 5657)

Restrições materiais que eliminam concretamente as escolhas possíveis - ainda que, em tese tais escolhas não sejam vedadas e seus efeitos reconhecidos e protegidos - limitariam, por assim, liberdade efetiva. A liberdade precisa ser instrumentalizada para a realização material. Nesse sentido, a liberdade efetiva poderia, sem excessos, ser definida como o conjunto 
capacitório que oferece a possibilidade de fato e real de se fazer aquilo que se valoriza como aspecto de relevo para a própria singularidade da existência individual.

Em resumo: a liberdade, aqui tratada - a liberdade sexual - deve ser instrumentalizada. A evidenciação das possibilidades da liberdade como uma função de tutela da personalidade colmata a própria dimensão funcional do Direito Civil contemporâneo, que toma por base um conceito plural de liberdade. A afirmação de uma função dos institutos de base do Direito Civil que pode consistir em propiciar o exercício, a proteção e o incremento de liberdades, situa-se no âmbito da tendência de personalização desse ramo do Direito, de modo coerente com os valores contemplados por um ordenamento jurídico centrado na pessoa humana. (TEPEDINO, 2008. p. 26)

Conclui-se que há na necessidade de se pensar a partir do que é jurídico, a inevitável inserção normativa do conteúdo material nas formas previstas, na situação da Ordem Constitucional democrática que assegura a liberdade como um direito fundamental. Por vezes, seguindo essa perspectiva, a limitação das funções do Direito Civil à não coerção (sentido negativo de liberdade) é insuficiente ante a extensão do comando constitucional, importando em "déficit de proteção" (RUZYK, 2011, p. 342).

Do contrário, pode ser precisamente a restrição da liberdade negativa de um indivíduo o modo pelo qual se incrementa a liberdade positiva e a liberdade material de outro indivíduo. Não há que se admitir, pois, a individualização atomizada do sujeito, haja vista que a autoconstituição individual é sempre intersubjetiva, inserida na rede de relações sociais que antecedem o próprio indivíduo: "ao mesmo tempo em que constrói sua subjetividade, ele é construído pela coexistência.

Assegurar de modo incondicionado a liberdade negativa de um indivíduo pode importar privações de liberdade substancial para o outro (como ausência de acesso ou mesmo supressão de funcionamentos básicos) - e, nessa medida, a privação pode ser superada o meio pelo qual se promove o lugar de não restrição à conduta daquele primeiro indivíduo. A alteridade é traço inevitável da liberdade. Essa alteridade, entretanto, não é mera justaposição de espaços reciprocamente delimitados externamente: ela implica interseção de vidas livres, o que importa a responsabilidade intersubjetiva recíproca pelas liberdades dos indivíduos em relação. Não se é livre sozinho: a liberdade é sempre coexistencial. É aí que a liberdade se encontra com a solidariedade.” (RUZYK, 2011, p. 310.)

Por ser considerada sempre em um contexto relacional, a liberdade não pode ser entendida em uma totalidade abstrata que transcenda a complexidade dos arranjos 
intersubjetivos. Não se deve advogar, por conseguinte, por uma liberdade objetivada: há de se buscar as finalidades múltiplas que podem encontrar referências nas bases do Direito Civil moderno, em contra sentido do organicismo funcionalista das formas. Proteger a liberdade e promover a vivência da liberdade: é em resumo uma das faces da funcionalização do Direito Civil em tutela da garantia constitucional. Desse modo, o pensamento jurídico não pode mais reduzir a liberdade a uma enunciação discursiva meramente formal, cujo exercício seja reservado apenas à setores específicos da sociedade - de acordo com a avaliação da historicidade do Direito Civil oitocentista (TEPEDINO, 2008. p. 34).

O enclausuramento da liberdade em fórmulas discursivas formais é contrária à afirmação do valor inerente da liberdade - da possibilidade efetiva de expressar e vivenciar a liberdade de escolher o próprio projeto singular.

\subsection{A PERSPECTIVA DA CONSTITUIÇÃO DA INTIMIDADE COMO UM DIREITO FUNDAMENTAL}

A intimidade, ainda que não positivada na legislação constitucional anterior, era considerada um elemento indispensável à dignidade humana, e, segue dela fazendo parte indeclinável, o que não significa afirmar que sempre fora protegida. Como todos os atos e construções humanas, a legislação constitucional é passível de uma série de imperfeições e imprecisões. Em se reconhecendo o caráter mutável e suscetível às políticas vigentes ao momento, tal percepção do fenômeno expõe os riscos aos direitos mais imediatos do ser humano.

Comparato sustenta que "[s]e se admite que o Estado nacional pode criar direitos humanos, e não apenas reconhecer sua existência, é irrecusável admitir que o mesmo Estado também pode suprimi-los, ou alterar de maneira tal o seu conteúdo a ponto de torná-los irreconhecíveis". (2003. p. 59).

Sob outra perspectiva, em complementação, o que pode ser afirmado é que o surgimento de um novo contexto social pode tornar mais evidentes as violações ao indivíduo, importando em realçar a necessidade da tutela específica de determinado bem jurídico, e do resguardo do direito em análise. É nesse sentido que Miguel Reale afirma que o direito passa a ter seu valor "revelado à consciência humana", e ser aceito como se fosse inato. (REALE, 1999. p. 214).

A despeito das possíveis descrições dos fenômenos jurígenos dos direitos constitucionais, seja por viés da tradição jusnaturalista ou da inclinação à disciplina positivista, 
a discussão parece - a certa medida - suplantada pelo reconhecimento explícito da intimidade como um direito fundamental. A intimidade é então um dos componentes da dignidade humana, de que brotam os demais direitos da personalidade, que constituem "uma unidade indivisível interdependente e inter-relacionada, capaz de conjugar o catálogo de direitos civis e políticos ao catálogo de direitos sociais, econômicos e culturais" (PIOVESAN, 2006. p. 183)

Diferentemente das Constituições anteriores, a Magna Carta de 1988 tratou de proteger a privacidade, declarando, no art. $5^{\circ}, \mathrm{X}$, que são invioláveis a intimidade, a vida privada, a honra e a imagem das pessoas, assegurando o direito a indenização pelo dano material ou moral decorrente de sua violação. Assim, a novel ordem constitucional oferece, expressamente, guarida ao direito à privacidade, que consiste fundamentalmente na faculdade que tem cada indivíduo de obstar a intromissão de estranhos na sua vida particular e familiar, assim como de impedir-lhes o acesso a informações sobre a privacidade e intimidade de cada um, e também proibir que sejam divulgadas informações sobre esta área da manifestação existencial do ser humano. (DA CUNHA JÚNIOR, 2009. p. 679).

Nesse sentido, a privacidade corresponde ao direito de ser deixado só (right to be let alone), ou ao direito de ser esquecido (right to be forgotten). $\mathrm{O}$ direito à intimidade é um direito especial ligado à essência do indivíduo, à sua personalidade, que consiste, na escorreita avaliação de Paulo José da Costa Jr., no "direito que dispõe o indivíduo de não ser arrastado para a ribalta contra a vontade. De subtrair-se à publicidade e de permanecer recolhido na sua intimidade. 'diritto alla riservatezza', portanto, não é direito de ser reservado ou comportar-se com reserva, mas o direito de manter afastados dessa esfera de reserva olhos e ouvidos indiscretos, e o direito de impedir a divulgação de palavras, escritos e atos realizados nessa esfera. É, em suma, o direito de proteção dos segredos mais recônditos do indivíduo, como a sua vida amorosa, a sua opção sexual, o seu diário íntimo, o segredo sob juramento, as suas próprias convicções. (DA CUNHA JÚNIOR, 2009. p. 668)

A proteção à intimidade encontra desdobramentos em outros direitos constitucionais, que também se ocupam da preservação dos aspectos da intimidade e da vida privada, como, por exemplo, o direito à inviolabilidade do domicílio e da correspondência, o sigilo profissional e das informações pessoais. No âmbito das relações privadas, a concretização deste valor normativo faz surgir deveres de consideração mútua e de confiança, haja vista que a intimidade também emana seus efeitos para as relações horizontais. Assim, além da garantia perante terceiros e contra o Estado - como sustento de uma obrigação negativa, a intimidade como valor axiológico-normativo da legalidade constitucional repercute na esfera privada para a 
defesa da individualidade em sua esfera mais reservado de recato: protegendo a expressão da sexualidade, na substância dos direitos sexuais, como o centro da gravidade para toda a consideração de que o ser humano tem um espectro de existência que encontra lugar no direito de ser deixado sozinho, de ser esquecido.

\section{CONSIDERAÇÕES FINAIS}

A tutela específica dos direitos fundamentais serviu, inicialmente, para a concepção de poderes jurídicos outorgados aos indivíduos para se protegerem contra a opressão do Estado: determinados pela tecnologia legislativa de regulação das relações entre o Estado e o indivíduo (BONAVIDES, 2000. p. 47).

No entanto, com a complexidade das relações sociais e a maior desigualdade entre os sujeitos, agravada pelo avanço da técnica e virtualização de comportamentos, fez-se notar que a opressão das liberdades não ocorria apenas por meio da atuação desproporcional do Estado, mas também que o próprio homem em sua relação de pares, demandavam a atenção específica do ordenamento democrático.

Daí a necessidade de se estender a eficácia dos direitos fundamentais às relações havidas entre os homens, com o fim de proteger o homem da prepotência do próprio homem, em especial de pessoas, grupos e organizações privadas [tão poderosas quanto a própria ordem estatal]" (DA CUNHA JÚNIOR, 2009. p. 612)

No Brasil, há uma tendência na doutrina que repercute na jurisprudência do STF, em se adotar a teoria da eficácia direta dos direitos fundamentais nas relações privadas, por todos, Luís Roberto Barroso:

O ponto de vista da aplicabilidade direta e imediata afigura-se mais adequado para a realidade brasileira e tem prevalecido na doutrina. Na ponderação a ser empreendida, como na ponderação em geral, deverão ser levados em conta os elementos do caso concreto. Para esta específica ponderação entre autonomia da vontade versus outro direito fundamental em questão, merecem relevo os seguintes fatores: a) a igualdade ou desigualdade material entre as partes (e.g., se uma multinacional renuncia contratualmente a um direito, tal situação é diversa daquela em que um trabalhador humilde faça o mesmo); b) a manifesta injustiça ou falta de razoabilidade do critério (e.g., escola que não admite filhos de pais divorciados); c) preferência para valores existenciais sobre os patrimoniais; d) risco para a dignidade de pessoa humana (e.g, ninguém pode se sujeitar a sanções corporais). (BARROSO, 2009. p. 141) 
Tal tendência corresponde a interpretação mais sistemática do $\S 1^{\circ}$ do art. $5^{\circ}$ da $\mathrm{CRFB}$, que determina a aplicabilidade imediata das normas de direitos fundamentais. Forte em tais razões, a construção teórica sobre os direitos sexuais ganha maior relevo na justaposição das interpretações das teorias sobre as liberdades do indivíduo, da igualdade e da garantia de que o sujeito tem ao gozo de uma esfera da privacidade.

A partir desse tronco de direitos, os desdobramentos de ordem prática ou construções teóricas são possíveis e necessárias para a realização do projeto de desenvolvimento das humanidades.

Sobre a natureza dos direitos fundamentais, deve haver aplicação imediata, independentemente de outras normas regulamentadoras. Todavia, ainda que a condição de fundamentalidade lhe garanta primazia e evidência à legislação infraconstitucional, há de se levar em consideração que, tal qual os demais direitos, a intimidade não é um valor absoluto, ainda que derive diretamente do conteúdo da dignidade humana.

Haverá situações em que mesmo os direitos e liberdades fundamentais entrarão em conflitos, limitando-se mutuamente: mas não se excluindo, pois há de prevalecer a tutela mais abrangente da dignidade. (SILVA NETO, 2006. p 11)

Quando se reconhece que a aplicação da lógica estritamente formal é insuficiente para se alcançar o resultado útil de uma aplicação do direito com base nos standards da justiça material, oportuniza-se o discurso mais realista de abordagens dos conflitos que podem existir entre direitos fundamentais e, ou valores normativos. Porque, das diversas consequências práticas que existem na assunção da lógica jurídica como uma lógica argumentativa, pode-se considerar que a equivocidade dos conceitos utilizados como base do discurso jurídico seja uma das mais basilares. Pois, há de se assumir que a hermenêutica constitucional trabalha com noções que, - se não derivadas da linguagem estritamente formal e técnica do Direito -, derivam da linguagem natural, que, por conseguinte é argumentativa, e supera a bilateralidade do verdadeiro/falso. O único limite para a linguagem é o uso desarrazoado e fora do que se considera adequado. (BRANCO, 2000. P. 182)

Nesse sentido, compreende-se o conflito entre direitos fundamentais e a disciplina dada ao princípio da proporcionalidade, como o desenvolvimento de normas que exigem a realização proibitiva e limitativa dos usos inadequados ou desnecessários de um direito fundamental (REZEK NETO, 2004, p. 48 et seq.).

Invoca-se a proporcionalidade como a utilidade de se resolver dilemas de interpretação constitucional representados pelo conflito entre princípios e valores constitucionais, aos quais 
se deve igual obediência, por ostentarem a mesma posição na hierarquia constitucional normativa.

Postula-se a existência de um "princípio dos princípios", que determina a busca de uma 'solução de compromisso', na qual se respeita mais, em determinada circunstância, um dos princípios em conflito, procurando desrespeitar o mínimo aos outros (MELLO, 2004. p. 407).

Por esse motivo, alguns o chamam de princípio de "otimização" dos direitos fundamentais. Como elementos do princípio da proporcionalidade, Bonavides aponta: 1) a pertinência ou aptidão, também chamado de adequação ou idoneidade, em sentido de que deve buscar a medida válida para alcançar o fim desejado; 2) a necessidade ou indispensabilidade, na escolha do meio menos gravoso de se obter a finalidade desejada; 3) a ponderação: como o sentido estrito do princípio, tomando por conta o esforço de preservar ao máximo cada um dos interesses envolvidos. (BONAVIDES, 2004. p. 395)

Especificamente sobre o direito sexuais, tem-se com o seu reconhecimento constitucional recente, certamente terá que de acomodar-se em meio às demais garantias e direitos, individuais e coletivos, da mesma Carta. Isso não significa que seja ela menos importante ou que deva ser, em regra, limitada, ao contrário: deve trazer elementos que garantam sua efetividade, até pelo princípio de que a lei não pode afastar da apreciação do Poder Judiciário lesão ou ameaça de direito.

Desse modo, a compreensão em profundidade das garantias e direitos fundamentais que informam a construção dos direitos sexuais é importante para a delimitação do relevo das áreas de interesse, de repercussão e de promoção para a defesa da dignidade sexual dos sujeitos de direito. $\mathrm{O}$ entendimento das fundações das estruturas condiciona o desenvolvimento das tecnologias de concretização do objetivo de desenvolvimento das humanidades. E saber que quão mais evidente é a garantia formal da qual decorre o programa social de defesa e promoção, maior é a chance de êxito do projeto social: pois importa reconhecer que à sombra dos direitos, existem os custos de realização efetiva dos mesmos: recursos financeiros e humanos.

\section{REFERÊNCIAS}

AGUSTINA, J. R, GÓMEZ-DURÁN, E. L. Sexting: Research criteria of a globalized social phenomenon. Archives of Sexual Behavior n.41, 2012. pp. 1325-1328. Disponível em \&lt;http://dx.doi.org/10.1007/s10508-012- 0038-0. Acesso em 26 de outubro de 2018. 
ALDERMAN, E.; KENNEDY-SCHLOSSBERG, C. The right to privacy. Nova Iorque: Alfred A. Knopf Inc., 1995.

ALEXY, Robert. Teoría de los derechos fundamentals. Trad. E. Garçon Valdés. Madrid: CEPC, 1993.

ARCHER, Robert. Sexuality and human rights. Genebra: International Council on Human Rights Policy, 2009.

ASCENÇÃO, José de Oliveira. Cláusulas gerais e segurança jurídica no CC de 2002. Revista Trimestral de Direito Civil, v. 28. Rio Grande do Sul: Padma, out/dez. 2006. . Pessoa, direitos fundamentais e direitos da personalidade.

Revista Trimestral de Direito Civil, v. 26. Rio Grande do Sul: Padma, abr/jun., 2006.

AZEVEDO, Antonio Junqueira. Caracterização jurídica da dignidade humana. In. Estudos e Pareceres de Direito Privado. São Paulo: Saraiva, 2004.

BARROSO, Luis Roberto. Constitucionalização do direito e direito civil. In. TEPEDINO, Gustavo. Direito civil contemporâneo: novos problemas à luz da legalidade constitucional. São Paulo: Atlas, 2008. Curso de direito constitucional contemporâneo: os conceitos fundamentais e a construção do novo modelo. São Paulo: Saraiva, 2009.

BELTRÃO, Silvio Romero. Direitos da Personalidade. São Paulo: Atlas, 2014.

BENOTSCH, E. G., MARTIN, A. M., SNIPES, D. J.,e BULL, S. S. Sexting, substance use, and sexual risk behavior in young adults. Journal of Adolescent Health, n. 52, 2013a. Pp. 307-313. Disponível em \&lt;http://dx.doi.org/10.1016/j.jadohealth\&lt; Acesso em 10 de julho de 2014.

significant associations between technology use and sexual risk: A need for more empirical attention. Journal of Adolescent

Health, n.53, 2013b. Pp.147-148. http://dx.doi.org/10.1016/j.jadohealth.2013.03.028 . Acesso em 10 de julho de

2014.

BRANCO, Paulo Gustavo Gonet. Aspectos de Teoria Geral dos Direitos Fundamentais. In.: hermenêutica constitucional e os direitos fundamentais. Brasília: Brasília Jurídica, 2000, p. 103-194.

BOBBIO, Noberto. Da Estrutura à função; Novos estudos de teoria do direito. Barueri: Manole, 2007.

BONAVIDES, Paulo. Curso de Direito Constitucional. 9a. Ed. Rev. atual. Amp. São Paulo: Malheiros, 2000.

CATONNÉ, Jean-Phillippe. A sexualidade, ontem e hoje. Trad. de Michèle Iris Korelak. São Paulo: Cortez, 
1994.

CHESSER, Brianna. Therapeutic jurisprudence. DOI: 10.1093/OBO/9780195396607-0203.

COMPARATO, Fábio Konder. A afirmação histórica dos direitos humanos. 4. ed. São

Paulo: Saraiva, 2003.

CORDEIRO, Antonio Menezes. Teoria Geral do Direito Civil / Relatório, Universidade de Lisboa, 1987. .Tratado de direito civil $V$. Parte geral:

legitimidade, representação, prescrição, abuso de direito, colisão de direitos, tutela privada e provas. Lisboa, Almedina, 2011. Tratado de Direito Civil

Português, I; Parte Geral, I, $2^{\mathrm{a}}$ Ed.. Almedina, 2000. $\mathrm{Da}$

Boa Fé no Direito Civil, Colecção Teses, Almedina, 2001.

COSTA JÚNIOR, Paulo José da. $O$ direito de estar só: Tutela penal da intimidade. $4^{\mathrm{a}}$ ed. Revista e atualizada; São Paulo: Revista dos Tribunais, 2007.

CUNHA, Leonardo Carneiro da. Jurisprudência e Competência. 2a Edição. São Paulo: Editora Revista dos

Tribunais, 2013.

CUNHA DE SÁ, Fernando Augusto. Abuso de direito. Almedina, 2005.

CUNHA JÚNIOR, Dirley da. Curso de direito constitucional. Editora Juspodium, 2009.

DE CUPIS, Adriano. Os direitos de Personalidade. Lisboa: Morais Editora, 1961.

DOTTI, R. A. A proteção da vida privada e Liberdade de informação: possibilidade e limites. São Paulo: Revista dos Tribunais, 1980.

FRANKS, Mary Anne. Drafting an Effective Revenge Porn Law: A Guide for Legislators. University of Miami, UMSL Rev., 2015. Disponível em:

\&lt;http://ssrn.com/abstract=2468823\&gt;; acesso em: 22 de agosto de 2015.

Forest Law Review, . CITRON, Danielle Keats. Criminalizing Revenge Porn. Wake

Vol. 49, 2014, p. 345 e ss.; U. of Maryland Legal Studies Research Paper No. 2014-1.

Disponível em: \&lt;

http://ssrn.com/abstract=2368946\&gt;. Acesso em 24 de Agosto de 2015.

Columbia Journal of

.Unwilling Avatars: Idealism and Discrimination in Cyberspace.

Gender and Law, Vol. 20, p. 224, 2011. Disponível em http://ssrn.com/abstract=1374533\&gt;. Acesso em 12 de agosto de 2015.

University of Miami . Combating Non-Consensual Pornography: A Working Paper.

School of Law. UMSL Rev. 2014. Disponível em:

http://dx.doi.org/10.2139/ssrn.2336537\&gt; Acesso em $12 \mathrm{de}$

setembro de 2015. 
FERNANDES, Milton. Proteção civil da intimidade. São Paulo: Saraiva, 1977

FERREIRA, Luis Eduardo e Silva Lessa. As tutelas jurídicas da exposição não consentida da intimidade sexual

no Brasil e nos Estados Unidos. In: III Colóquio de Pesquisadores em Direito, 2016, Caruaru. Anais do III

Colóquio Internacional de Pesquisadores de Direito. Recife: APPODI, 2016. p. 235-250. . A Construção de um Direito Democrático da

Sexualidade na Evolução dos Direitos Humanos e dos Processos de Cidadania. In: IV Congresso Internacional - Constitucionalismo e Democracia: o Novo Constitucionalismo Latino-americano, 2016, Rio de Janeiro. Direito,

gênero, sexualidade e racialidade: VI congresso internacional constitucionalismo e democracia: o novo

constitucionalismo latinoamericano. Santa Catarina: Conpedi, 2016. p. 240-259.1.

. O uso do pseudônimo como garantia do acesso à

justiça das vítimas

da exposição sexual não consentida: uma revisão sobre o segredo de justiça brasileiro com base na experiência

norte-americana.. Revista de Direito Brasileira - RDBras, 2017.

GROENINGA, Giselle Câmara. Direito e psicanálise: um novo horizonte epistemológico. In Afeto, ética, família e o novo Código Civil; coordenador Rodrigo da Cunha Pereira - Belo Horizonte: Del Rey, 2004.

personalidade. In

O direito à integridade psíquica e o livre desenvolvimento da

Família e dignidade humana. ANAIS - V Congresso Brasileiro de Direito de Família;

Rodrigo da Cunha Pereira. São Paulo: IOB Thompson, 2006.

JEWELL, Jennifer, BROWN, Christia Spears. Sexting, catcall, and butt slaps: How gender stereotypes and

perceived group norms predict sexualized behavior. Sex Roles, online first, December 2013, Volume 69, Issue

11, pp 594-604. Disponível em http://dx.doi.org/10.1007/s11199-013-0320-1. Acesso em 09 de abril de 2015.

KATZMAN, Debra. K. Sexting: Keeping teens safe and responsible in a technologically savvy world.

Paediatrics and Child Health 15. 2010. pp. 41-45. Disponível em:

http://dx.doi.org/10.1177/1473225411420533.

Acesso em 07 de julho de 2015.

KRISZTAN BORCSIK, Sandor. Do acompanhamento de processos gravados com 'segredo de justiça' pelo sistema informatizado do egrégio Tribunal de Justiça do Estado de São Paulo. 2007.

LÔBO, Paulo. Metodologia do direito civil constitucional. in. TEPEDINO, G. FACHIN, E. e LÔBO, P.

(Coord.) Direito Civil Constitucional: a ressignificação da função dos institutos fundamentais do Direito Civil 
contemporâneo e suas consequências. Florianópolis, Conceito Editorial, 2014. . Direito Civil: Parte Geral - 2ed. São Paulo: Saraiva, 2010.

MELLO, Celso Antônio Bandeira de. Conteúdo Jurídico do Princípio da igualdade. 3 ed., 14 tir., São Paulo: Malheiros, 2006.

MENDES, João de Castro. Direitos, liberdades e garantias - alguns aspectos gerais. In. Estudos sobre a Constituição. Lisboa: Livraria Petrony, v. 01: 93-116, 1997

MIRANDA, Jorge. Manual de Direito Constitucional. Coimbra: Editora Coimbra, 2004.

MORAES, Maria Celina Bodin de. Danos à pessoa humana: uma leitura civil-constitucional dos direitos morais. Rio de Janeiro: Renovar, 2003.

O conceito de dignidade humana: substrato

axiológico e conteúdo

normativo. In: SARLET, Ingo Wolfgang. (org.) Constituição, Direitos Fundamentais e Direito Privado. Porto

Alegre: Livraria do Advogado, 2006. p. 123

Revista Estado, Direito

. A Caminho de um Direito Civil Constitucional.

e Sociedade, vol. I, 1991, publicação do Departamento de Ciências Jurídicas da PUC-Rio. 1991.

NOVAIS, Jorge Reis. Direitos Fundamentais: trunfos contra a maioria. Coimbra: Coimbra Editora, 2006. . Princípios Constitucionais Estruturantes da República Portuguesa. Coimbra: Coimbra Editora, 2004.

NOVELINO, Marcelo. Manual de Direito Constitucional - Volume Único, $8^{\mathrm{a}}$ Ed. Editora Método, 2013.

PARKER, Richard. Sexuality, Health and Human Rights. Am J Public Health, 2007a; 97(6): p. 972-973.

$2007 b$. Culture, Society and Sexuality. 2a ed. Nova Iorque, NY: Routledge;

PIOVESAN, Flávia. Direitos humanos e o direito constitucional internacional. 4. ed. São Paulo: Max Limonad, 2006.

POSNER, Richard. Sex and Reason. Cambridge, MA: Harvard University Press, 1992.

POST, Stephen. Encyclopedia of bioethics. Macmillan Referense USA, Thompson Gale, 2004.

QUINTERO, Luz Anyela Morales; DÍAZ, María Belinda Aguilar. Justicia Terapéutica: barreras y oportunidades para su aplicabilidad en México. In: WEXLER, David B. et al. Justicia Terapéutica: experiencias y aplicaciones. Cidade do México: Instituto Nacional de Ciencias Penales, 2014. 
RAUPP RIOS, Roger. Para um direito democrático da sexualidade. Horizontes Antropológicos, Porto Alegre, ano 12, n. 26, p. 71-100, jul./dez. 2006

REZEK NETO, Chade. O Princípio da Proporcionalidade no Estado Democrático de Direito. Lemos \& Cruz: 2004.

ROSENVALD, Nelson. As funções da responsabilidade civil: a reparação e a pena civil. São Paulo: Atlas, 2013.

RUZYK, Carlos Eduardo Pianovski. Institutos fundamentais do Direito Civil e Liberdade(s): Repensando a dimensão funcional do contrato, da propriedade e da família. Rio de Janeiro: GZ Editora, 2011.

SARLET, Ingo Wolfgang. Direitos da pessoa humana e direitos fundamentais na constituição Federal de 1988. $8^{\mathrm{a}}$ ed. rev. atul. e amp. Porto Alegre: Livraria do Advogado Editora, 2010.

SARMENTO, Daniel. Direitos fundamentais e relações privadas. Rio de janeiro: Lumen juris, 2004.

SCHREIBER, Anderson. A proibição de comportamento contraditório: tutela da confiança e venire contra factum proprium, Rio de Janeiro: Renovar, 2005

. Direito Civil e Constituição. São Paulo, Atlas, 2013.

. Direito e Mídia. São Paulo: Atlas, 2013.

SILVA NETO, Manoel Jorge. Curso de Direito Constitucional. Rio de Janeiro: Lumen Juris, 2006.

SOUSA, Rabindranath V. A. Capelo de. O direito geral de personalidade. Coimbra: Coimbra Editora, 1995.

SOUZA, Carlos Affonso Pereira de Souza. Abuso do Direito nas Relações Privadas. Rio de Janeiro: Elsevier, 2013.

TARTUCE, Flávio. A indenização por revenge porn no Direito de Família Brasileiro. RJLB - REVISTA

JURÍDICA LUSO-BRASILEIRA, v. 1, p. 1985-1991, 2018.

TARTUCE, Flávio. Manual de direito civil. São Paulo: Método, 2013.

WEXLER, David B; PERLIN, Michael L Michel Vols et al. \&\#39;Editorial: Current Issues in Therapeutic

Jurisprudence; (2016) 16(3) QUT Law Review pp. 1-3. 
Therapeutic The Development of

Jurisprudence: From Theory to Practice, 68 Revista Juridica Universidad de Puerto Rico 691-705 (1999).

WORLD HEALTH ORGANIZATION. Defining sexual health, 2010. Disponível em: http://www.who.int/reproductivehealth/topics/sexual_health/sh_definitions/en/ . Sexual health, human rights and the law, 2014.

Disponível em:

\&lt;http://www.who.int/reproductivehealth/publications/sexual_health/sexualhealth-humanrights-law/en/. Acesso em 08 de fev.2015.

. Sexual and reproductive health and rights: a global

development, health, and human rights priority, 2015. Disponível em http://www.who.int/reproductivehealth/publications/gender_rights/srh-rights-comment/en/

definitions. Disponível em . Gender and reproductive health: working \&lt;www.who.int/reproductive- health/gender/sexual_health.html.\&gt; Acesso em 08 de fev.2015.

Trabalho recebido em 19 de fevereiro de 2019

Aceito em 05 de julho de 2020 